
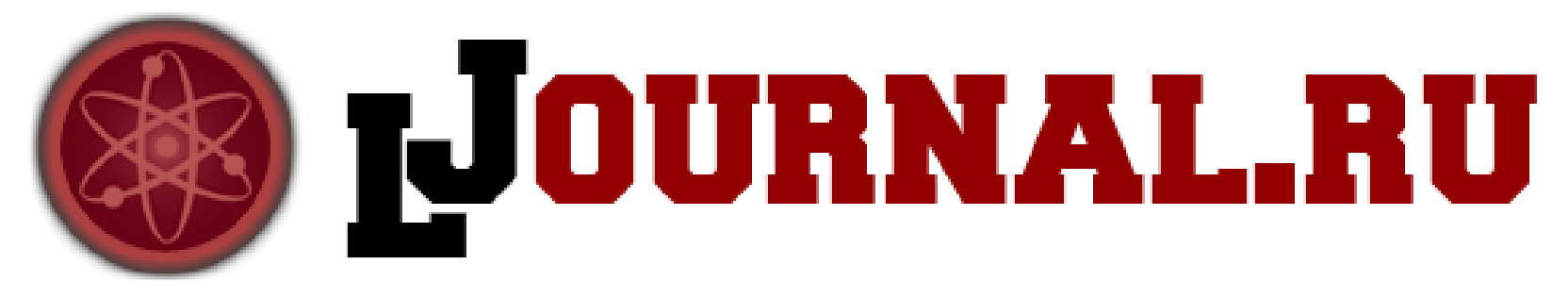

Костин К.Б., Горбачев И.А., Муктаров О.Д., Маркелова О.А., Дударева О.А., Лясникова А.В., Пичхидзе С.Я.

СГТУ имени Ю. А. Гагарина

Саратов, Россия

doi: 10.18411/1j2016-2-10

\title{
Идентификация магний-содержащего ТКФ
}

В настоящее время для ортопедии представляют интерес различные металл-замещенные фосфаты. Поэтому инструментальный анализ магнийсодержащих биоматериалов является необходимой частью исследования [1].

Цель работы заключалась в изучении метода получения магнийсодержащего трикальцийфосфата (Mg-TKФ).

Методика эксперимента. Оптимальным способом получения $M g$-TКФ является термическое взаимодействие $\mathrm{CaCO}_{3}$ и пирофосфата магния (ПФМ). $M g-T K \Phi$ получали в 2 этапа, 1-й: синтез ПФМ из хлорида и нитрата магния;

2-й: синтез $M g-T K \Phi:$

$$
\begin{gathered}
\mathrm{Mg}^{++}+\left(\mathrm{NH}_{4}\right)_{2} \mathrm{HPO}_{4}+\mathrm{NH}_{3}+6 \mathrm{H}_{2} \mathrm{O} \rightarrow \downarrow \mathrm{MgNH}_{4} \mathrm{PO}_{4} * 6 \mathrm{H}_{2} \mathrm{O}+2 \mathrm{NH}_{4}{ }^{+} \\
\mathrm{MgNH}_{4} \mathrm{PO}_{4}+\mathrm{H}_{2} \mathrm{O} \rightarrow \mathrm{MgHPO}_{4}+2 \mathrm{NH}_{4} \mathrm{OH} \\
2 \mathrm{MgHPO}_{4}{ }^{t} \rightarrow \mathrm{Mg}_{2} \mathrm{P}_{2} \mathrm{O}_{7}+\mathrm{H}_{2} \mathrm{O} \uparrow \\
2 \mathrm{MgNH}_{4} \mathrm{PO}_{4} * 6 \mathrm{H}_{2} \mathrm{O}^{t} \rightarrow \mathrm{Mg}_{2} \mathrm{P}_{2} \mathrm{O}_{7}+7 \mathrm{H}_{2} \mathrm{O} \uparrow+2 \mathrm{NH}_{3}{ }^{\uparrow} \\
\mathrm{Mg}_{2} \mathrm{P}_{2} \mathrm{O}_{7}+\mathrm{CaCO}_{3}{ }^{t} \rightarrow \mathrm{Mg}_{2} \mathrm{Ca}\left(\mathrm{PO}_{4}\right)_{2}+\mathrm{CO}_{2} \uparrow
\end{gathered}
$$

Результаты и их обсуждение. Структура синтетического ПФМ принадлежала $\alpha$ - $u \beta-\mathrm{Mg}_{2} \mathrm{P}_{2} \mathrm{O}_{7}$, карточки № 01-075-1055, № 01-072-2042 [2,3]. 
По данным РЭМ, $M g$-TKФ, полученный из двух форм $\mathrm{Mg}_{2} P_{2} O_{7}$, представляет собой частицы правильной формы с плоскими гранями. ИКС образцов $M g$-TKФ полностью соответствовал структуре соединения в форме $\mathrm{Mg}_{x} \mathrm{Ca}_{y}\left(\mathrm{PO}_{4}\right)_{2}$. Для структур, синтезированных из различных форм $\mathrm{Mg}_{2} \mathrm{P}_{2} \mathrm{O}_{7}$ в ИКС НПВО наблюдалась интенсивная полоса валентных колебаний группы $P O_{4}$ при $1000 \ldots 1100 \mathrm{~cm}^{-1}$. Полосы антисимметричных и симметричных валентных колебаний группы $P$-O-P проявлялись при $970 \ldots 980$ и $750 \ldots 740 \mathrm{~cm}^{-1}$, соответственно. Анализ удельной поверхности образцов $M g$-TKФ показал, что значения $S_{y d}$ и объем микропор при сплавлении при $1100{ }^{0} \mathrm{C}$ примерно одинаковы, табл. 1.

Таблица 1

Параметры синтезированных порошков

\begin{tabular}{|c|c|c|c|}
\hline № & $\mathrm{S}_{\mathrm{yд}}, \mathrm{M}^{2} / \Gamma$ & $\begin{array}{c}\text { Объем микропор, } \\
\mathrm{cm}^{3} / \Gamma\end{array}$ & $\begin{array}{l}\text { Средний размер } \\
\text { частиц, nm }\end{array}$ \\
\hline \multicolumn{4}{|c|}{$\mathrm{Mg}-\mathrm{TK \Phi} \mathrm{из} \beta-\mathrm{Mg}_{2} \mathrm{P}_{2} \mathrm{O}_{7}$} \\
\hline 1 & 1,56 & 0,001 & $420-600$ \\
\hline \multicolumn{4}{|c|}{$M g-T K \Phi$ из $\alpha-M g_{2} P_{2} O_{7}$} \\
\hline 2 & 1,36 & 0,001 & $400-600$ \\
\hline
\end{tabular}

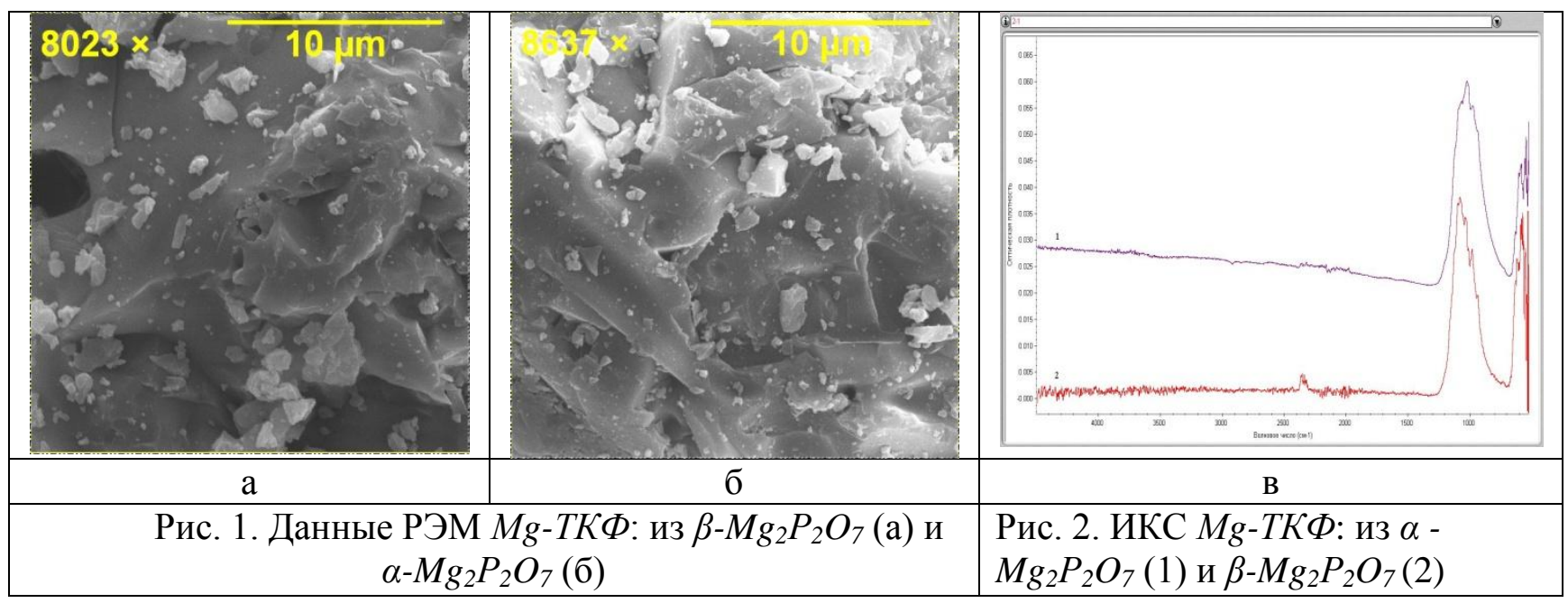

Выводы: 1) проведен твердофазный синтез $M g$ - $К К Ф$ из хлорида и нитрата магния; 2) доказана структура синтезированного $M g-T K \Phi$. 


\section{Литература:}

1. Баринов С. М., Комлев В. С. Биокерамика на основе фосфатов кальция. М.: Наука, 2005. - 204 с.

2. Lukaszewicz, K. Crystal structure of beta - Mg2P2O7. Rocz. Chem. 35, 1961. p.31.

3. Lukaszewicz, K. Crystal structure of alpha - Mg2P2O7 and the mechanism of the phase transition beta-alpha- Mg2P2O7. Bull. Acad. Pol. Sci., Ser. Sci. Chim. 15, 1967. - p.53. 